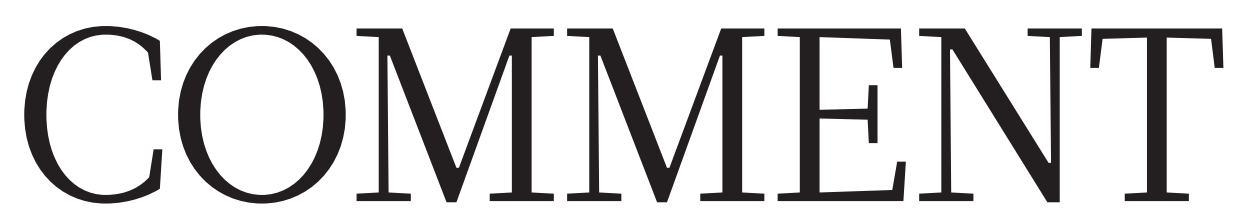

\begin{tabular}{l}
$\begin{array}{l}\text { EMERGENCIES Hurricane } \\
\begin{array}{l}\text { Sandy experience led to } \\
\text { disaster training } \mathbf{p . 4 3 0}\end{array}\end{array}$ \\
\hline
\end{tabular}

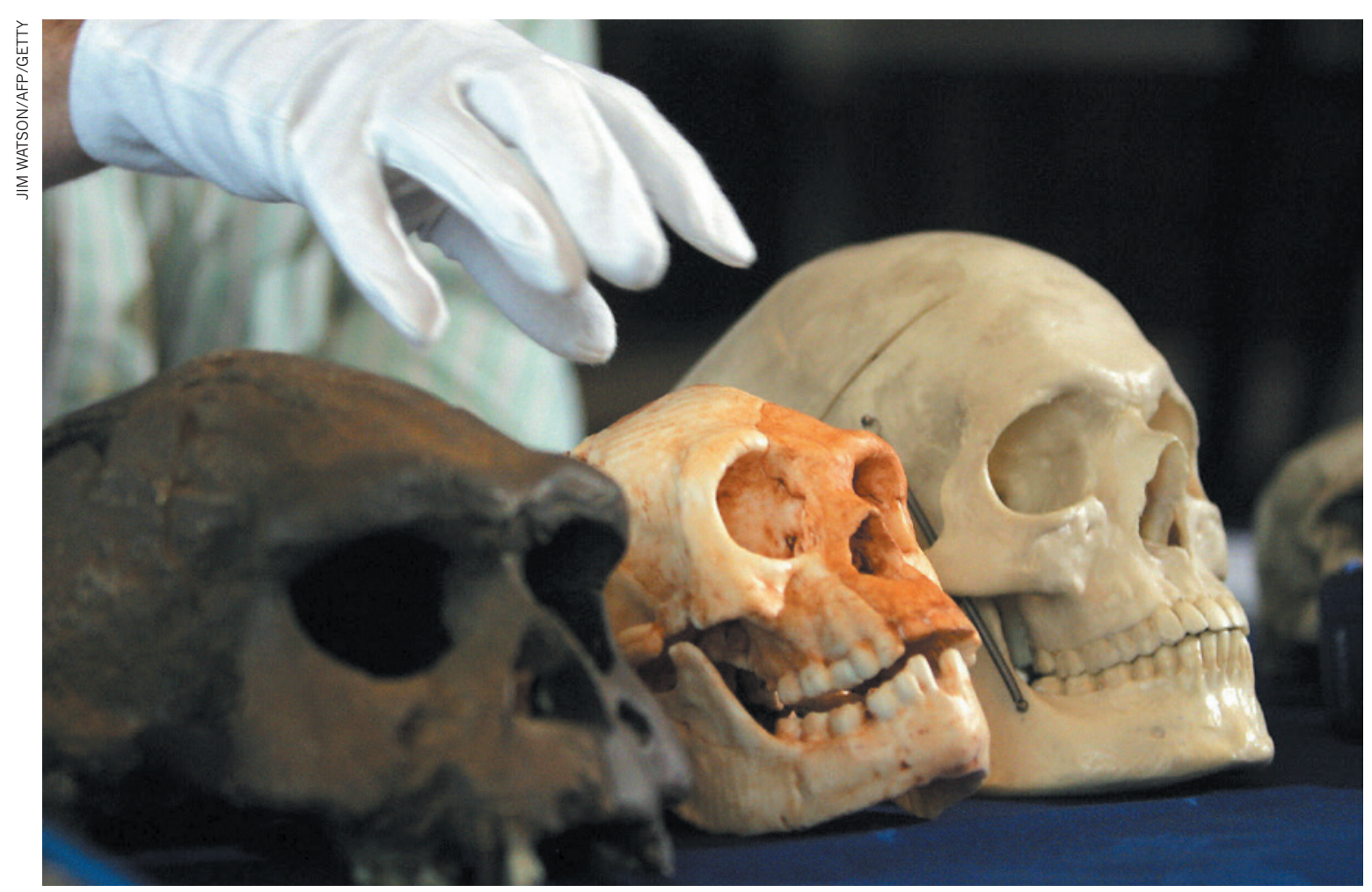

The adult skull of Homo floresiensis (centre) at the 2004 press conference announcing the species' discovery.

\title{
Small remains still pose big problems
}

Ten years after the publication of a remarkable find, Chris Stringer explains why the discovery of Homo floresiensis is still so challenging.

I n early 2004, the Australian palaeoanthropologist Peter Brown teasingly e-mailed 1 me pictures of a strange-looking skull, asking what I thought it was. I knew that he had been working in east Asia, so I guessed that the images might represent the first discovery of a very primitive member of our genus, Homo, from somewhere like China.

Gradually, Brown revealed the even more astonishing news of the skull's remote location and recent age. That October, he, Mike Morwood and colleagues published analyses in this journal ${ }^{1,2}$ with the controversial proposal that the tiny skull and its associated skeleton represented a new human species. They named it Homo floresiensis, which Morwood dubbed 'hobbit', owing to its diminutive stature - a moniker that the global press quickly ran with.

The researchers posited that a primi- $D$ NATURE.COM tive hominin persisted See Nature's online into the era of anatomi- special on the hobbit: cally modern humans ${ }^{2}$ nature.com/hobbitlo and lived in Flores, part of the remote string of Wallacean islands east of Java that have remained isolated since their formation (see 'How did the hobbit get to Flores?'). Controversy about this species continues to this day, including whether it even belongs in Homo.

\section{UNEXPECTED TRIP}

In 2004, like most palaeoanthropologists, I thought that only modern humans (Homo sapiens - like us) had travelled beyond southeast Asia in the past 60,000 years. 


\section{WHERE DOES THE HOBBIT BELONG?}

More than a decade after scientists unearthed a startling tiny skull, debate rages over which branch of the human tree bore Homo floresiensis.

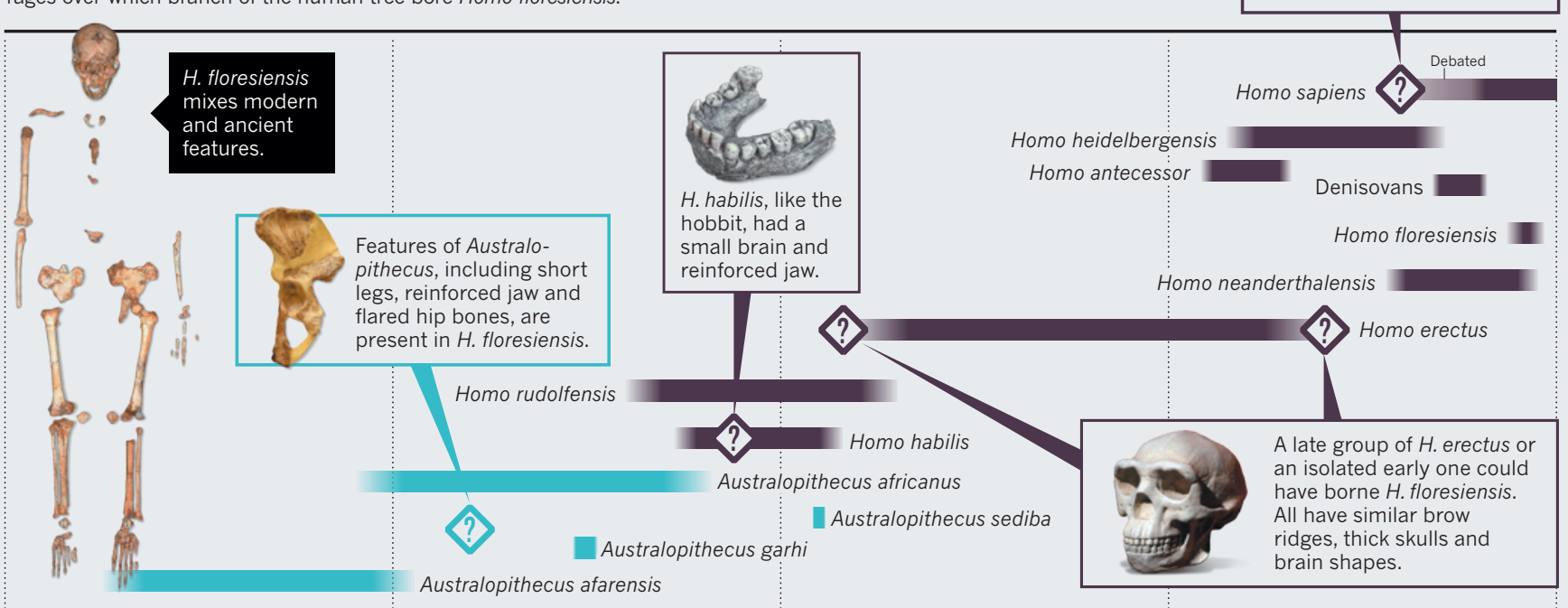

By then, people had devised sea-going watercraft essential for such a journey. It seemed unlikely that more-ancient humans could have made such a voyage ${ }^{3}$.

The excavations that first led to the idea that ancient humans did so began in 2001. Morwood, a New Zealand-born archaeologist, led an international team in the huge Liang Bua (meaning 'cool cave') on Flores, hoping to find evidence of the earliest modern humans to colonize Wallacea, Australia and New Guinea. The project reopened trenches several metres deep from previous Dutch and Indonesian work. It soon yielded promising finds: stone tools that seemed to be more than 10,000 years old, and fossils of a pygmy form of the extinct elephant-like Stegodon.

In 2003, at a depth of around 6 metres, the team encountered a small skeleton (LB1) that they first thought must represent a modern human child. Then they noticed other details: the wisdom teeth in its jaws had fully erupted, and the tiny skull showed definite brow ridges above its large eye sockets.

The skeleton was dated from associated materials to less than 20,000 years old. Morwood and colleagues argued that it represented a unique example of insular dwarfism in humans. This is a well-known process whereby large mammals isolated on islands evolve smaller bodies in response to limited resources and the lack of predators ${ }^{4}$.

Morwood and colleagues argued that a population of Homo erectus could have travelled, perhaps by boat, to Flores from Java (500 kilometres away), where $H$. erectus was first identified in the 1890s. Java, having been repeatedly connected to the rest of Asia over the past 2 million years when sea levels were low, was thought to mark the farthest extent from Africa of colonization by ancient humans. Morwood and colleagues posited that Flores's ancient settlers underwent island dwarfing, in parallel with other colonizing mammals such as Stegodon. Stone tools associated with Stegodon bones in Liang Bua suggested that $H$. floresiensis could have hunted and butchered these animals.

\section{ONGOING ARGUMENTS}

Stone tools discovered elsewhere on Flores, analyses of which were published ${ }^{5}$ in 2010, suggest that potential ancestors of $\mathrm{H}$. floresiensis could have been on the island a million years ago. But considering an island on the other side of the world - Britain with its discontinuous record of human settlement over 900,000 years, I can also imagine episodic human colonizations on Flores.

In 2009 , a collection of studies ${ }^{6}$ analysed LB1 in more detail, along with other fossils attributed to $H$. floresiensis, including

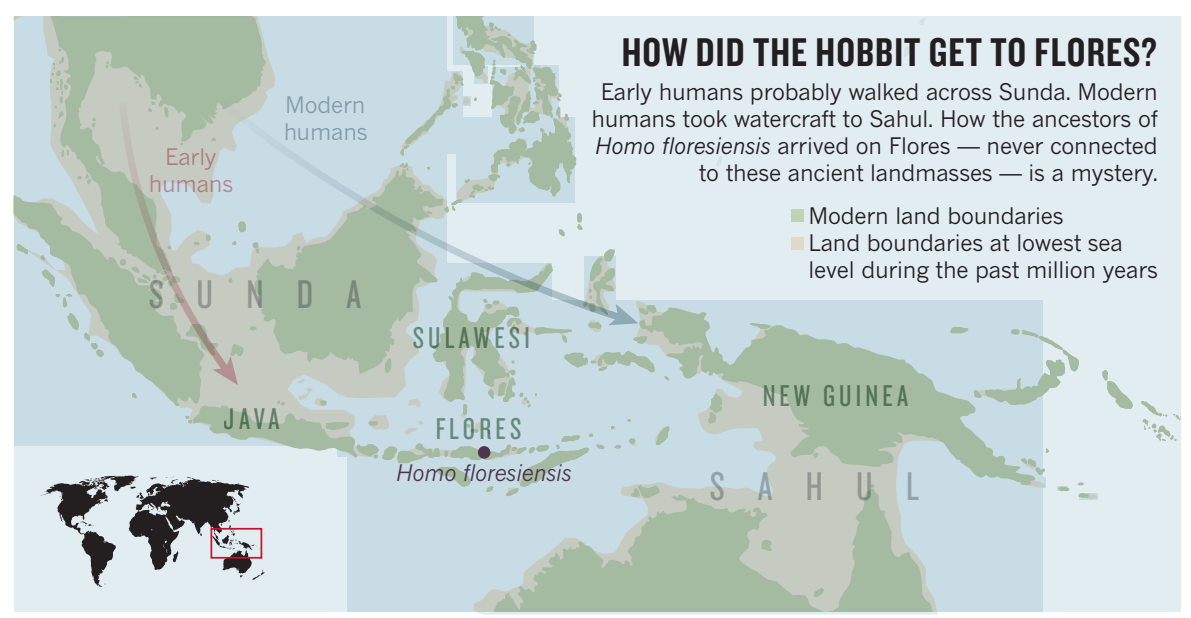

a second jawbone (LB6), and fragments of limb bones of up to eight more individuals. Features such as LB1's broad, flared hipbones, short collarbone, and forwardly positioned shoulder joint all resembled the pre-human group known as australopithecines ('southern apes'), which includes individuals such as the 3.2-million-year-old skeleton of 'Lucy', comparable in size to LB1.

These studies did not settle ongoing arguments about whether the finds represented a small, early human (a $H$. erectus shrunk through insular dwarfing) or an abnormal modern one, wrongly dated and analysed ${ }^{3,4}$. There were further problems: in late 2004, Teuku Jacob, a now-deceased Indonesian palaeoanthropologist, appropriated the specimens to conduct his own work in Yogyakarta. By the time the fossils were returned to Jakarta, following international pressure, some had been damaged irreparably ${ }^{4}$.

The small brain of $H$. floresiensis has 
provoked particularly fierce controversy. Some, citing parallels in other dwarfed mammalian species ${ }^{7,8}$, argue that it could derive from a $H$. erectus template, diminished but human in structural organization. Others rule out dwarfing, insisting that the braincase is much smaller than would be expected if a $H$. erectus body were scaled down. They argue that the shape of the brain reflects pathology - perhaps a condition called microcephaly.

Various pathologies can explain some of the unusual aspects of the LB1 skeleton. But in my view, no syndrome so far proposed can account for the totality of evidence from Liang Bua. Neither cretinism, Laron syndrome nor Down's syndrome duplicate the full suite of features.

\section{CLASSIFYING THE HOBBIT}

From the beginning, Brown and Morwood were torn over how to classify the fossil. In the first drafts of their paper they even created an entirely new genus for LB1 to reflect its unique combination of human and nonhuman traits - 'Sundanthropus floresianus'. But in the face of insistent reviewers, they shifted to the idea that their find was a dwarfed version of $H$. erectus ${ }^{4}$.

Both Morwood and Brown indicated later that they were not convinced by that model $^{6,10}$, and I join them in their doubts. The tiny brain of LB1, its body shape, and its foot, hand and wrist bones look more primitive than those of any human dating to within the past million years. Primitive traits of the wrist bones and jaw are replicated in at least one more individual from the site ${ }^{10,11}$. Like LB1, the LB6 lower jaw is small, lacks a chin, and shows internal bony reinforcements most like those in pre-human fossils more than 2 million years old ${ }^{10}$.

Ten years on, it is still very difficult to decide between competing views on where the hobbit came from (see 'Where does the hobbit belong?'). Island dwarfing from a local $H$. erectus population is probably still the most widely accepted idea, although this would require the re-emergence of primitive traits as well as convergence on $H$. sapiens in features such as tooth size and shape ${ }^{12}$.

A more primitive origin, from a more ancient $H$. erectus population (such as the 1.8-million-year-old fossils found at Dmanisi in Georgia) would require less extreme dwarfing, but would still need the re-emergence of primitive traits. An even more primitive template, closer to Homo habilis or the pre-human australopithecines, is a closer match for the reinforced jawbone, brain and body size, wrist morphology, and body shape, but would require still more convergences on later Homo morphology in features such as cranial thickness, retracted face and dental reduction.

We need more bones from Liang Bua to establish the morphological

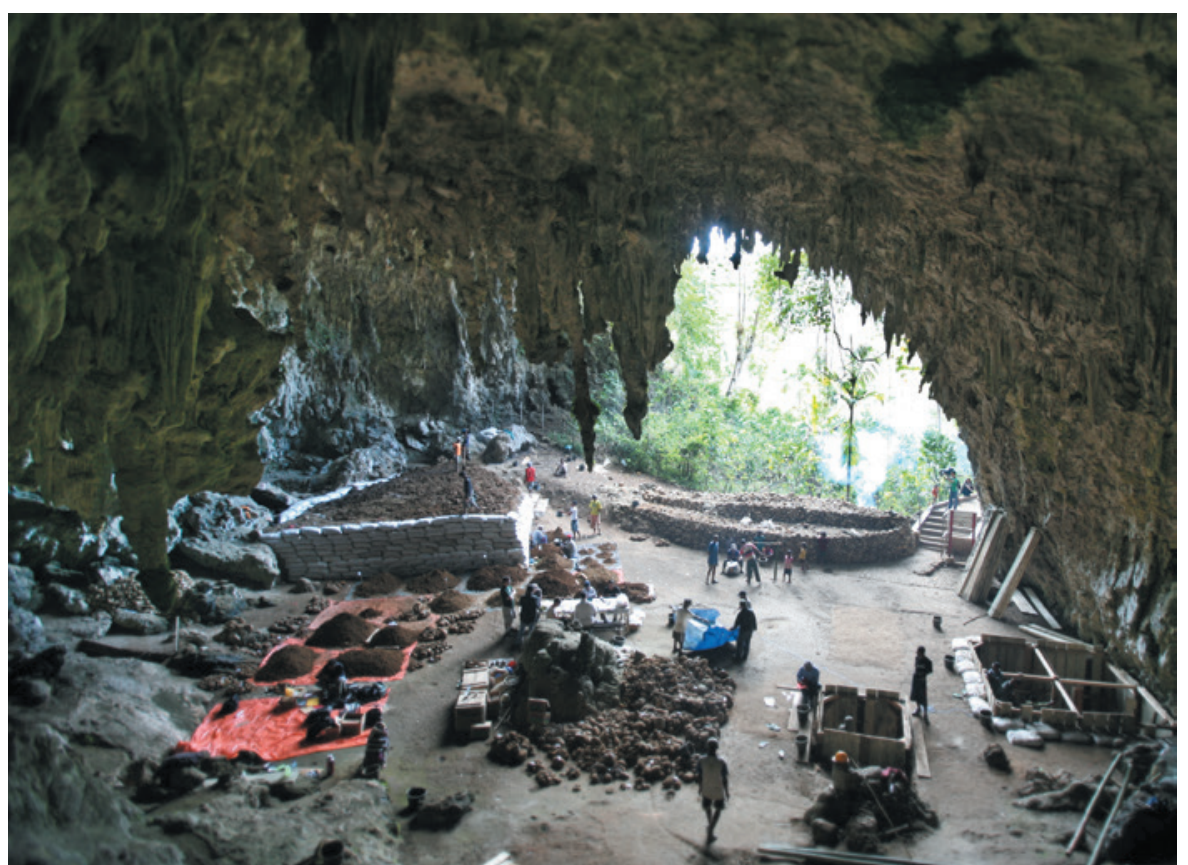

Liang Bua cave on the Indonesian island of Flores, the discovery site of Homo floresiensis.

variation of $H$. floresiensis and set pathological explanations to rest. At present we do not even know the extent of sexual dimorphism in the species - would a male skeleton be much larger and more $H$. erectus-like?

Isotope studies and analyses of preserved dental tartar could help to reconstruct the $H$. floresiensis diet, and investigations of dental microstructure might place the species taxonomically, because primitive hominins grew distinctly faster than $H$. erectus and later humans ${ }^{3}$. Even small amounts of ancient DNA would greatly clarify its evolutionary history, but it will require both technological breakthroughs and good fortune to acquire analysable samples from the warm, wet conditions of Liang Bua.

Significant work on re-evaluating the dates of the site, fossils and archaeology was under way before Morwood's untimely death in 2013. The results, due soon, will undoubtedly affect our views of $H$. floresiensis, and when and why it went extinct.

\section{MORE SURPRISES}

I think that there are more surprises to come from the rest of Wallacea. If the ancestors of $H$. floresiensis reached Flores, perhaps they also dispersed to other islands, and the experiment in human evolution revealed in Liang Bua might have equally remarkable parallels elsewhere - for example on Sulawesi, the Philippines and Timor. As Morwood pointed out $^{4,6}$, the powerful currents around Indonesia would have favoured transport from Sulawesi (north of Flores) rather than from Java, where the nearest $H$. erectus fossils have been found. The possibility of accidental rafting on mats of vegetation in such a tectonically active region must also be considered; in the 2004 Indian Ocean tsunami, some people who survived on floating debris were dispersed more than 150 kilometres.

If the $H$. floresiensis lineage had a more primitive origin than the oldest known $H$. erectus fossils so far identified in Asia, then we would have to re-evaluate the dominant explanation for how humans arose and spread from Africa. Most current thinking assumes that the first dispersal from Africa was just before the time of the Dmanisi fossils $^{3}$. An ancient origin for the hobbit would make that dispersal earlier and more complex $^{13}$. It would mean that a whole branch of the human evolutionary tree in Asia had been missing until those fateful discoveries in Liang Bua. aSEE NEWS FEATURE P.422

Chris Stringer is a research leader in human origins at the Natural History Museum in London, UK.

e-mail:c.stringer@nhm.ac.uk

1. Morwood, M. J. et al. Nature 431, 1087-1091 (2004).

2. Brown, P. et al. Nature 431, 1055-1061 (2004),

3. Stringer, C. The Origin of Our Species (Penguin, 2012).

4. Morwood, M. \& van Oosterzee, P. A New Human The Startling Discovery and Strange Story of the "Hobbits" of Flores, Indonesia (Harper Collins, 200).

5. Brumm, A. et al. Nature 464, 748-752 (2010).

6. Morwood, M. J. \& Jungers, W. L. J. Hum. Evol. 57, 640-648 (2009).

7. Falk, D. et al. J. Hum. Evol. 57, 597-607 (2009).

8. Kubo, D., Kono, R. T. \& Kaifu, Y. Proc. R. Soc. B 280, 20130338 (2013).

9. Vannucci, R. C., Barron, T. F. \& Holloway, R. L. Anat. Rec. 296, 630-637 (2013)

10.Brown, P. J. Hum. Evol. 62, 201-224 (2012).

11.Orr, C. M. et al. J. Hum. Evol. 64, 109-129 (2013)

12.Baab, K. L., McNulty, K. P. \& Harvati, K. PLOS ONE 8, e69119 (2013)

13.Dennell, R. \& Roebroeks, W. Nature 438, 1099-1104 (2005). 